\title{
Saberes Locais, Mediação e Cidadania: o caso dos agentes comunitários de saúde'
}

\section{Local Knowedge and Citizenship: the communitarian health}

agents

\author{
Gabriela Spanghero Lotta \\ Graduada e Mestre em Administração Pública, Doutora em Ciência \\ Política pela USP. \\ Endereço: Av. Luciano Gualberto, 315, Departamento de Ciência \\ Política. Cidade Universitária, CEP: 05508-900, São Paulo, SP, \\ Brasil. \\ Email: gabriela.lottaœgmail.com \\ I Pesquisa Financiada com Bolsa Capes e de Bolsa Fapesp. \\ Este artigo foi baseado no trabalho apresentado à $3^{\text {a }}$ edição do \\ Prêmio Sérgio Arouca de Gestão Participativa da Secretaria de \\ Gestão Estratégica e Participativa do Ministério da Saúde, 2008, \\ tendo recebido menção honrosa como "Trabalhos Acadêmicos".
}

\section{Resumo}

As discussões sobre o novo significado de cidadania, valorização da diferença e respeito à diversidade de saberes trazem a questão de como as políticas públicas podem ser localmente enraizadas para garantir que essa diversidade seja contemplada em seus processos. Esta incorporação é ainda mais relevante quando tratamos de políticas de saúde, onde a interação entre implementadores e beneficiários é essencial para compreender os resultados da política. O Programa Saúde da Família (PSF) tem tentado mudar as relações entre Estado e beneficiários, aproximando profissionais da saúde dos cotidiano vividos pelos beneficiários onde, muitas vezes, há (re)produção dos componentes que levam às situações de insegurança, insalubridade e doença. No caso desse programa, a análise das políticas públicas deve levar em conta os processos de interação e a ação dos atores envolvidos na implementação do PSF. Este artigo tem como objetivo analisar o papel dos Agentes Comunitários de Saúde enquanto implementadores do PSF. Através de pesquisas etnográficas acompanhando as atividades dos ACS em diferentes municípios, buscamos compreender como eles lidam com seus múltiplos saberes, ativam e desativam referências e adaptam ação para colocar em prática o Programa. A partir de análises de 24 Agentes Comunitários de diferentes municípios, avanlaos na compreensão de como se dão as mediações e as interações em suas práticas e como constroem as políticas públicas enraizando ações a partir dos cotidianos locais, construindo formas alternativas de implementação dessas políticas.

Palavras-chave: Agentes Comunitários de Saúde; Programa Saúde da Família; Implementação de Políticas Públicas; Políticas Públicas; Cidadania. 


\section{Abstract}

Discussions about the new meaning of citizenship, valuing differences and respecting knowledge diversity bring the question of how public policies can be locally rooted to ensure access to diversity. This is evident when we deal with health policies, where the interaction between implementers and beneficiaries is essential to understand the results of the policy. The Family Health Program (FHP) has tried to change the relationship between state and society, bringing health professionals with the daily experienced by the users where there is (re) production of the components that lead to insecurity, poor health and disease. To analyse this kind of policy we must take into account the interaction processes and the practices of the actors involved in the FHP implementation. This article aims to analyze the role of Health Communitarian Agents (HCA) as FHP implementers. Through ethnographic research followed the practices of ACS in different cities, we seek to understand how they deal with their different knowledge, enable and disable referrals and adapt action to enact the program. We want to understand how they use mediations and interactions in their practices and built policies locally rooted, constructing alternative ways to implement these policies. Keywords: Health Communitarian Agents; Family Health Programa; Public Policy Implementation; Public Policies; Citizenship.

\section{Introdução}

As recentes discussões sobre novos significados de cidadania, a valorização da diferença, a multiplicidade de valores e de interesses e o respeito à diversidade de saberes trazem à tona a questão de como as políticas públicas podem ser localmente enraizadas para garantirem a incorporação dessas diversidades em seus processos. Isso fica ainda mais evidente quando tratamos de políticas públicas de saúde, nas quais o componente de interação entre implementadores e beneficiários é essencial para compreender os resultados das políticas públicas.

A territorialização e o planejamento espacializado de políticas públicas permite privilegiar a percepção e compreensão das dinâmicas e relações que se dão no local e que demonstram a diversidade existente no mesmo. 0 olhar para o local, a territorialização das políticas e a participação de diversos atores em seu processo de construção parecem ser elementos centrais para a garantia desses novos padrões de cidadania. A forma de condução deste processo de diálogo de saberes e territorialização, no entanto, é algo ainda pouco sistematizado na literatura sobre políticas públicas de saúde.

Historicamente, o Programa Saúde da Família tem tentado mudar as relações entre os serviços de saúde e os e cidadãos, aproximando os profissionais da saúde do cotidiano vividos pelos beneficiários onde, muitas vezes, há a (re)produção dos componentes que levam às situações de insegurança, insalubridade e doença. No caso desse programa, por exemplo, a análise das políticas públicas deve levar em conta os processos de interação (entre seus implementadores e entre estado e socidade), bem como os vários atores envolvidos na implementação e, principalmente, a discricionariedade e as práticas dos burocratas inseridos no Programa. Um olhar alternativo às políticas públicas de saúde, portanto, nos permite considerar os diversos elementos existentes e como esses processos se concretizam e levam a resultados efetivos nas políticas.

Este artigo tem como objetivo realizar uma análise mais abrangente das políticas públicas de saúde, em especial do Programa Saúde da Família. Assim, analisando o papel dos implementadores do programa, os Agentes Comunitários de Saúde (ACS), 
nos propomos a compreender como eles lidam com seus múltiplos saberes, ativam e desativam relações e adaptam suas formas de ação para colocarem em prática o programa. Pretendemos, portanto, compreender como se dão as mediações e as interações em suas práticas e como constroem as políticas públicas enraizando suas ações a partir do cotidiano local, construindo formas alternativas de implementação dessas políticas.

Em termos metodológicos, primeiramente foi realizada uma revisão bibliográfica com o levantamento de teorias referentes à agenda de reformas e da nova cidadania - enquanto direito à eqüidade e à diferença, políticas públicas e territórios locais. Em seguida analisamos o papel dos mediadores para compreender como a construção de práticas a partir da mediação permite construir políticas com base nas dinâmicas e realidades locais.

Para a presente análise, foi selecionado o Programa Saúde da Família. Embora diversos outros programas pudessem ter sido analisados, a escolha do PSF se deu por seu histórico baseado em lutas sociais e pela figura do Agente Comunitário de Saúde (ACS) - já reconhecido na literatura como elemento importante na transformação das políticas de saúde.

Os resultados práticos apresentados aqui são provenientes de uma pesquisa (Lotta, 2010 e 2006) realizada desde 2004 e que tem como objetivo observar como os agentes de implementação estabelecem suas práticas e interações cotidianas e quais os resultados disso para as políticas públicas. Os resultados apresentados são provenientes de pesquisas de campo realizadas com agentes comunitários de saúde nos municípios de Sobral (CE), Londrina (PR) e Taboão da Serra (SP) (Lotta, 2010 e 2006).

A escolha destes três municípios foi estratégica no sentido de contemplar diferentes experiências que poderiam gerar aprendizados interessantes. Sobral e Londrina são consagrados pela literatura como experiências exitosas, embora diferentes. Enquanto a primeira está mais ligada a estratégias comunitárias, a segunda tem uma história mais ligada à medicina formal. Já Taboão da Serra passa por um processo mais recente e iniciante de implementação do PSF, que ainda está em fase de adaptação e que, portanto, traz questões relevantes para a análise de como os ACS se comportam em relação à política pública.

Os dados apresentados aqui são provenientes da pesquisa de, diretamente, 24 ACS dos três municípios. Os dados primários foram coletados a partir de pesquisas etnográficas por meio de acompanhamento dos ACS em todas as suas atividades durante uma semana: as visitas domiciliares, as reuniões e demais ações dentro das UBS, suas interações com a equipe, eventos oficiais da prefeitura e encontros da associação dos ACS, além de festas e encontros informais. Ao longo dessas observações etnográficas foram sendo sistematizadas asa falas e interações estabelecidas (com outros ACS, com usuários e com outros profissionais), bem como as ações por eles desenvolvidas.

A partir do levantamento destas informações, foram sistematizadas categorias que contemplassem as formas como os ACS organizam suas interações e, portanto, os processos de mediação. Estas interações, como serão demonstradas a seguir, são essenciais para garantir que a política pública se enraíze nas práticas locais e que, portanto, gere resultados positivos para a cidadania e participação.

Este artigo está dividido em três partes, além da introdução. Na primeira parte faremos uma revisão da literatura a respeito dos principais conceitos sobre a Agenda de Reformas, Nova Cidadania, Saberes Locais e Processos de Mediação. Na segunda parte apresentaremos a análise relativa às pesquisas de campo, organizadas a partir de: conceituação do trabalho do ACS, visões do poder público e da população em relação ao ACS e mecanismos e práticas de mediação. Por fim, serão apresentadas as análises e conclusões finais.

\section{Revisão da Literatura}

\section{Agenda das Reformas e Nova Cidadania}

Até os anos 8o, as políticas públicas de saúde eram marcadas por centralização decisória no governo federal. Aos municípios cabia unicamente o papel de executarem as políticas formuladas e controladas centralmente, de forma que se estabelecia uma relação com base em troca de favores entre as três esferas de governo. Além disso, a fragmentação institucional, a falta de articulação e o caráter setorial 
das áreas dificultavam a coordenação das políticas, resultando em baixa eficiência, eficácia e efetividade das mesmas (Farah e Barboza, 1999).

A sociedade civil também era praticamente excluída dos processos de decisão,, pois estava alijada da hierarquia da máquina estatal.

As lutas e movimentos sociais ocorridos durante os anos 80 e 90 na América Latina trouxeram para a agenda das políticas públicas brasileiras a luta por direitos. No Brasil, essa luta se refletiu na elaboração da Constituição Federal de 1988, que teve como critérios a democratização dos processos decisórios e a equidade dos resultados das políticas públicas. As propostas enfatizavam a participação dos cidadãos e a descentralização na formulação e implementação das políticas públicas, no espírito da concepção universalista dos direitos sociais.

Neste contexto, ao analisar a entrada da idéia de cidadania na agenda, Gaventa e Jones (2002) apontam que o foco em desenvolvimento participativo e a discussão dos projetos comunitários nos anos 90 criaram espaço na política para a participação de marginalizados e pobres, valorizando sua influência nas decisões que afetam sua vida. Também ajudou neste processo a questão da boa governança e sua ligação com o governo descentralizado, bem como o aumento da responsividade do governo quanto às necessidades e prioridades da população. Estes autores ainda apontam que os anos 90 abriram espaço para novas relações entre direitos humanos e desenvolvimento, reafirmando a participação como um direito humano e a cidadania como pré-requisito para os outros direitos.

O conceito de nova cidadania passou a fazer parte da agenda de políticas públicas brasileira. A nova cidadania trabalha com uma redefinição da idéia de direitos com a concepção do direito a ter direitos (Dagnino, 1994). Isto não se limita a conquistas legais, ao acesso a direitos definidos ou à implementação de direitos abstratos e formais - isto inclui o reconhecimento de novos direitos que emergem de lutas concretas. A disputa é também pela fixação do conceito de direito e pela afirmação dos direito. Nesta concepção, diversos autores apontam a idéia da cidadania enquanto o direito à igualdade e, ao mesmo tempo, o direito à diferença (Dagnino, 1994; Pierucci, 1994; Lavalle, 2003). Na nova cidadania, “o desafio enorme reside em encontrar novos modelos que possibilitem não apenas preservar defensivamente a equidade, mas ampliá-la com efetividade universal sem abrir mão da diferença" (Lavalle, 2003, p. 92). As idéias de igualdade e diferença enquanto direitos levam à inserção de componentes como identidade, cultura e território na disputa acerca das políticas públicas.

\section{Políticas Públicas: garantindo eqüidade e diver- sidade}

Diversos autores (Ribeiro, 1991; Diegues, 1992; Koga, 2003) que discutem a questão da diversidade e da territorialização das políticas públicas argumentam que o desenvolvimento local só se efetiva se baseado em padrões característicos de cada local, e que essa localização é a única maneira de garantir a cidadania. Para Ribeiro (1991), as categorias culturais locais não devem ser tomadas como impedimento ao crescimento econômico, mas como parte central de sua sustentabilidade. A respeito de sociedades sustentáveis, Diegues (1992) afirma que a própria definição do conceito de desenvolvimento deve ser feita com base nos valores culturais locais: são essas particularidades que, levadas em conta em processos de desenvolvimento, possibilitam o advento de sociedades sustentáveis. "O conceito de sociedades sustentáveis [...] possibilita a cada uma delas (as sociedades) definir seus padrões de produção e consumo, bem como o de bem-estar a partir de sua cultura, de seu desenvolvimento histórico e seu ambiente natural" (Diegues, 1992: 25).

Para Koga (2003), atualmente as políticas públicas tendem a uma normalidade e descrição de um tipo que não é fato real. As características locais são homogeneizadas e não ganham diferenciação na efetivação das políticas públicas. No entanto, a vida da população se dá em condições concretas, espacializadas, peculiares, nas quais o território e suas condições são essenciais. Dessa forma, "o lugar faz a diferença” (Sen, 200o, citado por Koga, 2003, p. 20).

Pensar na política pública a partir do território exige também a consideração da história, do cotidiano, do universo cultural da população que ali vive. Levar em conta a cultura local não significa, no entanto, que somente a solidariedade comunitária pode enfrentar as situações de exclusão social, mas 
sim o reconhecimento, por parte do Estado, das particularidades enraizadas na sociedade que precisam ser consideradas no processo de desenvolvimento. Trazer a vertente territorial significa trazer novos elementos para o debate da ética e da cidadania, o que implica considerar a dimensão cultural das populações, as particularidades, os locais onde vivem e se relacionam e suas vontades (Koga, 2003).

Para Autés (1991), as políticas territoriais são capazes de elaborar fórmulas inéditas de gestão do vínculo social. O lugar, então, realmente faz diferença como agente motor da engrenagem das políticas. A partir da relação entre políticas e território, podem ser introduzidas novas formas de gestão. $\mathrm{O}$ autor explica que a lógica dessa relação entre políticas e território "parte de um conhecimento comum sobre o lugar, contando com a participação dos sujeitos locais. Programas e projetos preestabelecidos ou elaborados em nível central [...] podem ser pouco úteis na montagem estratégica das políticas territoriais" (Autes, 1991, citado por Koga, 2003, p. 230). Apesar de ser essencial a necessidade de se olhar para o local no desenvolvimento de políticas públicas, não há ainda consenso sobre como esse processo pode ou deve ser feito.

A partir dos resultados do Programa Gestão Pública e Cidadania, Farah e Barboza (1999) analisaram práticas inovadoras que têm surgido na administração municipal. Para eles, uma das características aparentes é o reconhecimento nas políticas públicas da diversidade dos beneficiários, rompendo ainda mais o modelo padronizado e centralizado. Esse processo se dá, entre outras coisas, com a participação da sociedade civil nas políticas públicas, que passam a ter voz e influência nas definições e decisões. Para eles, ainda, o enraizamento das políticas na sociedade civil e no próprio Estado contribui para a continuidade das iniciativas.

Considerar o lugar e as pessoas que nele vivem como portadores de opinião, críticas, conhecimentos e saberes da realidade implica em uma refundação do território, na qual a participação das pessoas estabelece uma conjugação necessária para a prática da cidadania e da civilidade (Martin, 1998, citado por Koga, 2003, p. 247). Assim, "ao intervir num lugar, o projeto também vira constitutivo desse mesmo lugar (...). O mundo social é caracterizado pela presença simultânea de saberes múltiplos que emergem e são transmitidos de diversos cotidianos" (Spink, P., 2001, p. 12). Mas, para isso é preciso insistir em um conhecimento sistemático da realidade, que introduza a perspectiva da análise territorial na construção das políticas públicas. "O território representa uma forma de fazer valer as diferenças sociais e culturais que também deveriam ser consideradas no desenho das políticas públicas” (Koga, 2003, p. 53).

Considerar a cultura dentro das políticas públicas, no entanto, não é fácil, já que é preciso dar atenção ao contexto para formular as intervenções (Rao e Walton, 2004). A dificuldade está justamente em conduzir o processo, em como levar em conta as características culturais locais no desenvolvimento das políticas públicas. Para isso, a literatura aponta a importância de estímulo à participação, experiência e aprendizado com o local.

Nessa discussão sobre territorialização e enraizamento das políticas públicas, há conceitos centrais de análise, como a própria concepção de local, suas dinâmicas, seus cotidianos, seus espaços, seus lugares; e a questão dos saberes locais e processos de mediação destes saberes.

\section{Saberes locais e Mediação}

O lugar está em constante construção e "é aquilo que temos, sem nada além”. Tem horizontes e limites produzidos e disputados por nós mesmos. Neste sentido, Koga (2003) afirma que os processos de exclusão têm claras referências espaciais e temporais, de forma que não podem ser desvinculados da realidade onde se inserem. Enraizamento, territorialidade, encontro, confronto, disputa, proximidade, cultura e relações são alguns termos que surgem nesta definição de local e lugar.

Para abordar a questão do lugar é preciso ter um olhar que considere a complexidade, o que é cotidiano, quais são os limites e as conexões, as partes e o todo, os saberes e as crenças, pois "é no lugar que se concretiza a sociedade civil (Spink, P., 2001, p. 11)". E este olhar para o local, para seu cotidiano, para seus saberes e suas práticas significa olhar para a sociedade civil e sua interação com o Estado. Neste sentido, a idéia de políticas públicas territorializadas passa necessariamente pela incorporação daqueles que promovem a interação entre 
Estado e sociedade, ou seja, os implementadores de políticas públicas. A consideração destes implementadores nos auxilia a compreender como as políticas incorporam as dinâmicas locais, já que estes atores podem construir processos de mediação entre os usuários, a sociedade civil e o Estado.

Os autores que estudam o papel dos mediadores na implementação das políticas atribuem ao funcionamento complexo do Estado à existência e à necessidade de mediação. Schmidt (1977) aponta que o aumento da complexidade e a incompreensibilidade do Estado e da burocracia nacional levaram à necessidade de um mediador que pudesse traduzir ou interpretar os processos para as comunidades, ou seja.

O conceito de mediador, amplamente desenvolvido por Wolf (1956), engloba um indivíduo ou grupo de indivíduos que agem como elos, mediando grupos ou indivíduos totalmente separados entre os sistemas sociais local e o sistema nacional. Para ele, os mediadores são pessoas que guardam as conjunturas críticas ou as sinapses da relação que conecta um local com um sistema mais amplo. Os mediadores podem ser entendidos como elementos de uma forma particular de relação entre a parte e o todo e são, assim, indivíduos que conseguem operar em ambos os domínios, da comunidade e da nação (Wolf, 1956).

Ao observar os agentes de implementação como mediadores entre o poder público e a sociedade, vemos em nossos estudos uma nova concepção de mediação, na qual não se unem mundos completamente segmentados, mas sim mundos que possuem múltiplas formas de encontros e nos quais os agentes de implementação, muitas vezes, não possuem monopólio no estabelecimento da relação que pode, mesmo sob risco de falhas, acontecer de outras formas. Aqui, portanto, adotamos uma concepção de mediação que permite olhar para atores que não estão em completa desconexão, ao menos não estrutural. Um novo conceito aponta para olhar mediação como prática comunicativa na intersecção de grupos parcialmente desconectados, envolvendo conciliações provisórias entre os grupos (Mische, 2007). Nesta definição, incluímos um componente performativo baseado na própria comunicação, onde a mediação não se dá apenas para a construção de pontes relacionais (elos entre pessoas), mas sim no conteúdo das relações, como veremos em seguida.

No nosso estudo, ainda, consideramos que o processo de mediação dos agentes implementadores se dá a partir de dois movimentos: 1) estes agentes levam as idéias, práticas e ações das políticas públicas para o público beneficiário, 2) estes agentes trazem as idéias, informações e necessidades do público beneficiário para dentro do aparato estatal.

Considerando a importância do olhar para os agentes implementadores e a possibilidade de mediação estrutural e de conteúdo que eles trazem, é importante analisarmos o papel dos Agentes Comunitários de Saúde inseridos no Programa Saúde da Família, observando como eles constroem essas conexões e como, de forma discricionária, constroem suas práticas para implementação dos programas de saúde. Para tanto, agora retomaremos um pouco do histórico do PSF para, em seguida, apresentar as análises realizadas em relação aos ACS.

\section{Desenvolvimento}

\section{Programa Saúde da Família e o Papel dos Agentes Comunitários de Saúde}

Diversas políticas públicas criadas a partir da Constituição Federal de 1988 buscavam garantir a nova cidadania, como direito à igualdade e à diferença, bem como os componentes territoriais para se assegurar isso.

Um exemplo bastante consolidado neste sentido, e que se concretizou como extensa reforma dos serviços públicos é do Programa ou Estratégia de Saúde da Família (PSF). O PSF foi criado a partir de um amplo debate entre profissionais de saúde que conseguiram transformá-lo em uma diretriz federal implantada pelos diversos municípios.

O PSF integra um conjunto de medidas de reorganização da atenção básica, na perspectiva da reorientação do modelo de atenção à saúde da população no âmbito do SUS. Busca garantir atenção básica com a prestação do serviço nos próprios domicílios - com objetivo de humanizar o atendimento, abordar a saúde dentro do contexto social e intervir sobre fatores de risco das residências. (MS, 2006).

A estrutura prevista para a composição das equipes do PSF é: um médico, um (a) auxiliar de enfer- 
magem, um (a) enfermeiro (a), quatro a seis agentes comunitários de saúde. Em princípio, cada equipe responsável por uma área geográfica que engloba de 600 a 80 famílias. Atualmente, o Programa tem cerca de 28.000 equipes atuando em $80 \%$ dos municípios brasileiros, o que abrange cerca de 65 milhões de pessoas (35\% da população brasileira).

Para garantir a atenção direta às famílias, o PSF tem como figura central o Agente Comunitário de Saúde (ACS). A figura do ACS tem origem na experiência no Estado do Ceará, em 1987, com o duplo objetivo de criar oportunidade de emprego para as mulheres na área da seca e, ao mesmo tempo, contribuir para a queda da mortalidade infantil. Esta estratégia se expandiu no estado em três anos, abrangendo todos os municípios cearenses em 1991, e foi encampada pelo Ministério da Saúde no Programa Nacional de Agentes Comunitários de Saúde (PACS).

A incorporação do PACS no PSF, em meados dos anos 9o, trouxe a figura do ACS para um papel central de desenvolver ações nos domicílios de sua área de responsabilidade e junto à unidade de saúde, responsável pela programação e supervisão das atividades dos agentes.

O ACS é uma pessoa da própria comunidade que está preparada para orientar as famílias a cuidarem de sua saúde e da saúde comunitária. Ele age vinculado a uma unidade de saúde e atende aos moradores de cada residência da região sob sua responsabilidade.

Em 2006, uma portaria do Ministério da Saúde revisou e consolidou todas as legislações anteriores, definindo as funções e responsabilidades de cada categoria da equipe do PSF. Segundo essa portaria, passou a ser responsabilidade dos ACS:

"I - desenvolver ações que busquem a integração entre a equipe de saúde e a população adscrita à UBS, considerando as características e as finalidades do trabalho de acompanhamento de indivíduos e grupos sociais ou coletividade; II - trabalhar com adscrição de famílias em base geográfica definida, a microárea; III - estar em contato permanente com as famílias desenvolvendo ações educativas, visando à promoção da saúde e a prevenção das doenças, de acordo com o planejamento da equipe; IV - cadastrar todas as pessoas de sua microárea e manter os cadastros atualizados; V - orientar famílias quanto à utilização dos serviços de saúde disponíveis; VI - desenvolver atividades de promoção da saúde, de prevenção das doenças e de agravos, e de vigilância à saúde, por meio de visitas domiciliares e de ações educativas individuais e coletivas nos domicílios e na comunidade, mantendo a equipe informada, principalmente a respeito daquelas em situação de risco; VII - acompanhar, por meio de visita domiciliar, todas as famílias e indivíduos sob sua responsabilidade, de acordo com as necessidades definidas pela equipe; e VIII - cumprir com as atribuições atualmente definidas para os ACS em relação à prevenção e ao controle da malária e da dengue". (MS, 2006).

Para cumprir suas ações, os agentes comunitários podem estar ligados a uma UBS ou serem membros de uma equipe do PSF. O ACS “é uma pessoa da própria comunidade, que vive vida igual à de seus vizinhos, mas que está preparado para orientar as famílias a cuidarem de sua própria saúde e também da saúde de sua comunidade" (MS, 2005). Os agentes são selecionados entre os moradores da comunidade que, em geral, já apresentam tendência de atenderem a algumas demandas das famílias na sua vizinhança. Entre os pressupostos, eles devem ter idade mínima de 18 anos, saber ler e escrever, residir na comunidade há pelo menos 2 anos.

Embora a Portaria 648 detalhe as ações realizadas pelos ACS, quando analisamos sua atuação percebemos que existe uma diferença muito grande entre as práticas a eles determinadas e a forma como as executam e implementam, em especial quando se trata do momento de interação e mediação com as famílias usuárias do programa. Com esta constatação, algumas pesquisas têm sido realizadas no país sobre a atuação dos agentes comunitários no PSF, buscando analisar a inserção dos ACS nas políticas públicas e compreender o papel dos ACS enquanto mediadores entre as comunidades e o poder público (Silva e Dalmaso, 2002; Lotta, 2006, 2008a e 2008b; Nogueira, 2005).

Também sob esta perspectiva, temos realizado, há quatro anos, análises com diversos ACS que busca compreender como eles realizam a interface entre os saberes locais e as políticas públicas. A partir das pesquisas realizadas em três municípios brasileiros 
concluímos, como mostraremos em seguida, que os ACS, por estarem inseridos na comunidade em que trabalham, se tornam um elo ou uma ponte entre os serviços públicos e os usuários. Assim, as pesquisas têm demonstrado que os trabalhos dos agentes se estendem às orientações da saúde e, na prática, eles se tornam o elemento de proximidade entre os cidadãos e o poder público (Lotta, 2006, 2008a, Lotta 2008b; Lotta e Pavez, 2008). Em seguida demonstraremos as análises relativas à atuação dos ACS em três diferentes municípios: Sobral, CE, Londrina, PR e Taboão da Serra, SP.

\section{Visões em relação aos ACS}

Uma das questões centrais para analisar o papel dos ACS como mediadores e implementadores de políticas públicas é compreender a visão que os diversos atores envolvidos têm em relação a seus trabalhos. Neste sentido, analisando a interação entre usuários, ACS e profissionais, levantamos informações de como o poder público e os usuários do programa compreendem o trabalho e a função dos ACS. Vale ressaltar que as informações abaixo não foram levantadas a partir de entrevistas ou questionários, mas sim são citações transcritas a partir da observação do processo de interação entre os atores, de forma espontânea, nas relações cotidianas de implementação do PSF.

Para os profissionais do poder público (médicos, enfermeiras, auxiliares de enfermagem, coordenadores do programa, etc.) prevalece uma percepção de que os Agentes Comunitários são, ao mesmo tempo, reconhecidos como profissionais da saúde e têm grande atuação como Agentes da comunidade em si. Neste sentido, é recorrente ouvir frases dos profissionais como, por exemplo, "o ACS sabe quem deve ser medicado, visitado, alfabetizado. Ele traz as ações e ajuda a construir o planejamento porque éele quem vivencia a realidade da comunidade".

$\mathrm{Ou}$, ainda, "o agente de saúde é bom porque ele é um 'elo de ligação'. É ele quem traz as necessidades e leva as possibilidades para a população. Ele é a base da promoção da saúde". E "a importância dos agentes está em falar a linguagem que o outro entende e é por isso que os agentes ganham espaço nas equipes de saúde".

Há, no entanto, uma barreira clara quando se trata da questão de ampliar o foco de atuação dos
ACS. Para os profissionais de saúde, os ACS têm um papel delimitado de acompanhar as famílias, trazer as demandas e levar informações. Aparecem diversos conflitos nos quais os profissionais das equipes não concordam em dar aos ACS alçada para realizar outras ações, por exemplo realizar grupos ou atividades educativas, alguns procedimentos básicos (como medir temperatura, etc.) ou mesmo mexer nos prontuários. Assim, embora se reconheça a importante inserção comunitária dos ACS, os profissionais colocam limites formais em suas atividades, em especial devido à falta de formação técnica em saúde dos ACS.

Já em relação ao poder público, há uma visão clara de que os agentes desenvolvem trabalhos que vão além das políticas de saúde e que permitem maior integração entre estado e soceidade além da expectativa de que a sociedade se aproprie mais das práticas por eles desenvolvidas. Neste sentido, é comum que a prefeitura peça aos ACS para desempenhar atividades que extrapolam o limite direto das ações de saúde (como cadastro no programa bolsa família, seleção de famílias para alfabetização, indicação de crianças para creche, etc.). Ao mesmo tempo em que isso poderia significar um desvio de função, a delegação dessas atividades aos ACS demonstra o reconhecimento do poder público quanto à capacidade e envolvimento comunitário desses atores.

Com relação à comunidade, o trabalho realizado pelos agentes é reconhecido como algo que pertence a seu cotidiano, que é indivisível das dinâmicas locais, na medida em que os próprios ACS pertencem a esse espaço e a essa dinâmica. A própria comunidade estabelece com eles uma relação mais próxima que se sustenta pelo reconhecimento das relações e do pertencimento dos agentes àquele espaço. Assim, percebe-se que este reconhecimento permite ao trabalho dos ACS ser integrado ao cotidiano da comunidade.

Ao mesmo tempo, há a percepção clara de que os ACS são profissionais do poder público, de forma que se demanda a eles resoluções, informações e benefícios além de suas responsabilidades. É comum, por exemplo, encontrar situações em que a população pergunta para os ACS como conseguir vaga em creche, se têm informações sobre emprego, sobre cursos profissionalizantes, casas para alugar, 
como conseguir laudos para aposentadoria, como registrar crianças, etc. Podem ser vistos também diversos pedidos para que os ACS resolvam problemas comunitários como coleta de lixo, barulho na vizinhança, falta de higiene dos vizinhos, etc.

Assim, de forma geral, os ACS são vistos tanto pelo poder público como pela comunidade como agentes do poder público - que trabalham além das ações em saúde - e para quem podem ser solicitados serviços, informações, favores, etc. Ao mesmo tempo, são vistos como pessoas pertencentes à comunidade, que sabem a linguagem própria para conversar com as pessoas e com quem a comunidade estabelece relações próximas e de confiança, além do reconhecimento enquanto liderança comunitária. Em seguida veremos quais são as práticas e mecanismos que permitem aos ACS serem reconhecidos como estes duplos pertencimentos - comunitário e burocrático.

\section{Práticas e Mediação}

Uma segunda questão a ser analisada é forma como os ACS estabelecem práticas e mecanismos de mediação que permitem a eles se tornarem este elo entre Estado e usuários. Assim, a fim de compreender como os ACS atuam enquanto mediadores, como constroem suas práticas e implementam as políticas públicas, acompanhamos estes profissionais em diversas visitas, durante as quais repertoriamos as práticas. Apresentamos a seguir uma sistematização desse levantamento, para identificar como estes implementadores atuam e como lidam com diferentes saberes.

A partir dos acompanhamentos, identificamos quatro práticas, ou mecanismos correntes nas práticas dos ACS que nos ajudam a compreender como eles constroem suas ações: a) ACS utilizam referências da comunidade em suas práticas; b) ACS intercalam saberes adquiridos enquanto profissionais da política de saúde e saberes próprios de suas vivências; c) ACS realizam tradução de saberes; d) ACS fazem triangulação.

\section{ACS utilizam referências das vivências comunitá- rias em suas práticas}

Os burocratas implementadores criam e utilizam referências em seus discursos para torná-los mais próximos e compreensíveis para a comunidade, a partir de elementos que remetam o que eles querem dizer a situações do passado ou ao cotidiano dos usuários. Entre as referências mais comuns estão: histórias da comunidade; familiares dos usuários; pessoas comuns (amigos, familiares, conhecidos); histórias vividas pelos próprios ACS; situações compartilhadas; religião; e à história de saúde do paciente.

A partir do uso destas diversas referências, algumas exemplificadas em seguida, os ACS trazem elementos do cotidiano dos beneficiários para o processo de implementação da política pública.

Uma das referências mais comuns é a religiosa. Durante as visitas domiciliares, muitas vezes os ACS falam de Deus e aconselham a rezar. Outras vezes, dizem que estão rezando e fazem promessas para algum paciente melhorar, pedem ou dão a bênção para os usuários, etc. São comuns frases como "Deus abençoe que dê tudo certo"; "Graças a Deus"; "Fique com Deus"; "Vai ficar bem, graças a Deus".

Outra referência bastante comum é em relação aos familiares, na qual o ACS se refere a algum familiar do usuário para legitimar ou reforçar sua recomendação, como demonstrado nesta situação: em visita a uma mulher que não queria fazer pré-natal o agente diz: "vou avisar teu pai que tu não quer ir no médico. Ele vai ficar bem bravo com você".

Por fim, com relação à referência a casos vividos pelos próprios ACS, é comum que eles respondam a questões ou situações dos usuários com frases como: "eu já passei por isso", "sei como é isso", ou "quando aconteceu comigo e eu agi da seguinte forma [...]". Utilizando sua própria experiência enquanto exemplo, os ACS conseguem construir ações de educação para a saúde de forma mais legitimada e concreta, que permite aos usuários compreenderem, aceitarem e adotarem as recomendações feitas.

ACS intercalam saberes locais e saberes técnicos da saúde

Nos processos de interação com os beneficiários ou com os funcionários do serviço público, os ACS transitam entre o uso de linguagens técnicas, orientadas pela política pública, e linguagens denominadas aqui de saberes locais. Estes saberes são aquelas linguagens utilizadas comumente pelos beneficiários e que passam a fazer parte das rotinas de prática dos implementadores. 
Em muitas visitas e diálogos se realizam discursos que variam entre o saber adquirido enquanto profissional de saúde e o saber que vem das vivências comunitárias dos agentes. Há, ao mesmo tempo, no discurso dos agentes, um papel didático de ensinar as famílias e tornar o conhecimento mais acessível a elas. Os agentes, portanto, estabelecem suas rotinas de trabalho variando o discurso entre os saberes e tornando as instruções mais compreensíveis para a população. Seguem abaixo alguns exemplos desta prática.

Em visita a uma criança com dor de garganta, o ACS pergunta o que a mãe está dando a ela. A mãe responde que dá chá de quiabo e que não levará a criança ao médico porque já está sendo medicada. O ACS então responde, intercalando saberes: "mas é remédio caseiro. Nem sempre é bom só remédio caseiro, dê a ela também mel, não deixa ela descalça e nem na terra quente. $\varepsilon$ se não funcionar, a gente trazo médico".

Em outra ocasião, em visita a uma criança gripada, a ACS aconselha a mãe: "pode dar mel. Mas se continuar com febre e não conseguir comer, você leva para rezar, depois dá umas gotinhas (de paracetamol) e leva no posto".

Em visita a uma puérpera, a ACS aconselha a mãe: "você precisa dar apenas leite materno, exclusividade por seis meses pra criança ficar bonita e não ter gripe. Mas lembra de passar o leite no bico do peito pra ele não rachar".

\section{ACS traduzem saberes}

Os agentes comunitários muitas vezes buscam traduzir as linguagens técnicas para linguagens utilizadas pelos beneficiários, de forma a se fazerem entender, legitimarem suas ações e se aproximarem dos usuários. Em diversas situações pode-se perceber na prática dos ACS a busca de traduzir os saberes médicos para os populares e vice-versa. Os agentes desempenham, nesses casos, uma função didática, na tentativa de se fazerem entender e legitimarem suas ações.

Diversas situações demonstram este processo, como por exemplo: uma senhora chama o ACS na rua e diz que não entendeu a receita médica. O ACS pega os três remédios, examina a receita e diz: "tu tá vendo esse laranja? Ele lembra suco que a gente toma de manhã, então tu toma esse laranja todas as manhãs e esses dois remédios brancos tu toma com leite, que também é branco, na hora de dormir".

Ou em outro momento, em que o ACS traduz um conhecimento: em uma visita a uma puérpera, por exemplo, a agente explica para a mãe sobre a assadura na pele do bebê: "Não pode usar talco porque o talco tampa os poros do pulmão. O pulmão é cheio de furinho, que nem a nossa pele onde nascem os pelos que é cheio de furinho para respirar. O talco é tão fino que pode tampar os furinhos do pulmão".

\section{ACS realizam triangulações}

Os ACS realizam triangulações entre os beneficiários da política pública e outros burocratas, em especial demais profissionais da equipe do PSF. Neste processo, intermedeiam fisicamente o processo de interação. Esta triangulação pode estar associada à idéia de tradução apresentada acima, mas ela vai além, no sentido de intermediar relações e não apenas traduzir os saberes adquiridos na saúde para saberes mais cotidianos.

Neste sentido, são bastante comuns cenas em que os agentes conversam com um paciente e com a enfermeira ou médico ao mesmo tempo, dizendo para um o que o outro disse. Os ACS, nessas situações, realizam triangulações inclusive fisicamente, se colocando entre os profissionais de saúde e a população.

São também comuns situações em que os ACS escrevem um papel e pedem para os usuários entregarem para os profissionais da equipe, contendo alguma recomendação ou recado que permita ao outro profissional compreender o que o usuário precisa. Uma das situações, por exemplo, dizia: "(nome da paciente) precisa fazer exame de sangue com urgência para poder marcar a consulta com a ginecologista. Marque para ela para amanhã". Além do papel, os ACS também realizam uma espécie de triangulação com tradução quando ensinam aos usuários o que devem dizer para médicos e enfermeiros, para se fazerem entender ou poderem ser atendidos. Neste caso, a triangulação é ainda mais forte quando os ACS, por exemplo, dizem "você chega lá na enfermeira, e fala que eu mandei dizer que você precisa de um exame".

Por fim, outro exemplo de triangulação aparece quando os ACS se oferecem para buscar e entregar os medicamentos na casa dos usuários, levar pedidos e 
marcar exames e consultas, ou, ainda, acompanhar os usuários dentro do posto para ajudar a marcar algum procedimento.

\section{Discussão e Conclusões}

Ao observar a prática dos ACS como agentes de implementação, podemos perceber que eles realizam uma transição entre a vida comunitária e a vida burocrática na hora de criarem e utilizarem seus saberes. A partir do uso de referências, de traduções ou de triangulações, os ACS variam entre os saberes adquiridos enquanto profissionais de saúde e aqueles saberes adquiridos por suas vivências comunitárias. Há, portanto, uma intercalação de saberes que permite aos agentes legitimarem suas práticas tanto com a população como com o poder público. Além desta legitimidade, a intercalação permite que os ACS estabeleçam um elo, ou uma ponte, entre estes atores, facilitando o diálogo e a troca de saberes e de conhecimentos.

A atuação dos ACS se dá diretamente ligada ao cotidiano, na medida em que eles fazem parte das dinâmicas locais, compreendem as relações e, inclusive, estão inseridos nelas. Assim, conseguem utilizar saberes adquiridos por conviverem com este cotidiano e trazer novas reflexões adquiridas em sua formação e em suas relações com os profissionais da saúde. Há, portanto, na ação dos agentes comunitários uma inter-relação de saberes, construídos local e exteriormente, e é em suas práticas cotidianas que eles realizam uma negociação entre os saberes e produzem suas próprias ações baseadas em sua forma de ver o mundo.

Ou seja, os ACS participam das dinâmicas locais, estão inseridos nos processos localmente construídos (e reconhecidos como tal) e são portadores desses saberes em seu trabalho com a comunidade, ao mesmo tempo em que são formados externamente com saberes produzidos longe do território e que se colocam como saber cientificamente comprovado. Em sua prática, os agentes oscilam o tempo todo entre estes saberes, somando-os para constituir um saber novo que possa dialogar com ambos. Dessa forma, ao mesmo tempo em que se utilizam dos saberes presentes no espaço, eles trazem elementos do Estado e levam para ele os elementos do local.
Ou seja, eles conseguem garantir que esses saberes locais sejam incorporados, inclusive como constituintes da política pública. Neste sentido, os ACS se utilizam dos saberes adquiridos pela profissão ressignificando-os com base em seus próprios conhecimentos, no senso comum da comunidade em que estão inseridos, tornando os saberes apropriados e inseridos nas diversas situações.

As práticas de ressignificação de saberes podem ser vistas ainda quando os agentes passam a desempenhar uma função de tradução ou uma função didática, tornando os conhecimentos mais acessíveis para a comunidade e para os profissionais de saúde, o que reforça a idéia de que eles se tornam mediadores no sentido mais comunicacional (Mische, 2007).

Pensando ainda na função de mediação, na medida em que a prática destes agentes impacta diretamente na vida dos cidadãos, os ACS passam a tomar decisões redistributivas e alocativas do serviço: determinam a elegibilidade dos beneficiários dos serviços. Suas decisões afetam diretamente as chances e oportunidades de vida dos indivíduos, o que tem conseqüências na forma como são recebidos pelos cidadãos e nas expectativas que as pessoas criam sobre seu trabalho (Lipsky, 1980).

Nessa mediação, os ACS conectam o mundo do Estado ao mundo da comunidade na medida em que, por um lado, possuem ambas as linguagens e, por outro, conhecem o cotidiano das pessoas possibilitando inserir as práticas da saúde neste cotidiano.

As atribuições dadas aos agentes pelo poder público possibilitam uma mediação em duas direções: ao mesmo tempo em que transmitem informações e cuidam da saúde da população a partir do sistema médico oficial, eles conseguem trazer para a política pública alguns elementos do cotidiano e da vida das pessoas, permitindo que as políticas sejam estabelecidas de acordo com as necessidades, demandas e vivências locais.

É a partir desta perspectiva que podemos ver que a ação dos agentes enquanto mediadores permite estabelecer ações e relações que vão além das práticas da saúde, trabalhando a partir das referências de direitos, educação, mobilização, entre outras. Assim, por estarem inseridos na comunidade, e criarem uma conexão com o Estado, ACS possibilitam que 
as políticas de saúde não se restrinjam à idéia da saúde como cura de doenças, mas sim que a promoção de saúde esteja ligada à promoção de ambientes e situações melhores para as pessoas.

No intuito de garantir a melhoria das políticas públicas, sua apropriação e o respeito a saberes, as análises anteriores permitem reforçar a idéia de o poder público estabelecer canais de mediação entre a população e a política pública por meio de agentes comunitários.

Assim, a análise da atuação dos ACS, enquanto agentes de implementação, permite perceber que a prática das políticas públicas varia de acordo com fatores relacionados ao cotidiano de sua implementação. As relações dos agentes com o território, com as pessoas e suas relações e vivências trazem novas formas e dinâmicas para dentro das políticas, que se transformam diretamente na implementação.

Assim, a partir das análises realizadas, o presente trabalho conclui que a inserção de agentes de implementação nas políticas públicas transforma as mesmas e que, apenas a partir da análise do trabalho desses agentes é que podemos compreender como as políticas públicas realmente se efetivam, quais seus impactos e resultados na prática e como essas inserções podem aprimorar as ações do poder público.

\section{Referências}

DAGNINO, E. Os movimentos sociais e a emergência de uma nova noção de cidadania. In: DAGINO, E. (Org.). Anos 9o: política e sociedade no Brasil. São Paulo: Brasiliense, 1994. p. 103-115.

DIEGUES, A. C. Desenvolvimento sustentável ou sociedades sustentáveis: da crítica dos modelos aos novos paradigmas. São Paulo em Perspectiva, São Paulo, v. 6, n. 1-2, p. 22-29, 1992.

FARAH, M. F.; BARBOSA, H. Apresentação. In: FARAH, M. F.; BARBOSA, H. 20 Experiências de gestão pública e cidadania. Programa Gestão Pública e Cidadania. São Paulo: EAESP-FGV/ Fundação Ford, 1999. p. 7-19.
GAVENTA, J.; JONES, E. Concepts of citizenship: a review. Development Research Centre on Citizenship, Participation and Accountability (IDS). Brighton: IDS, 2002. n. 19.

KOGA, D. Medidas de cidades. São Paulo: Cortez, 2003.

LAVALLE, A. Cidadania, igualdade e diferença. Revista Lua Nova, São Paulo, n. 59, p. 76-93, 2003. LIPSKY, M. Street-level bureaucracy: dilemmas of the individual in public service. New York: Russell Sage Foundation, 1980.

LOTTA. G. S. Saber e poder: agentes comunitários de saúde aproximando saberes locais e políticas públicas. 2006. Dissertação (Mestrado em Administração Pública e Governo) - Fundação Getúlio Vargas, São Paulo.

LOTTA. G. S. Estilos de implementação: ampliando o olhar para análise de políticas públicas. In: ENCONTRO DE ADMINISTRAÇÃO PÚBLICA E GOVERNANÇA, 3., 2008, Salvador. Anais... Rio de Janeiro: Anpad, 2008a. 1 CD-ROM.

LOTTA. G. S. Agentes de implementação: um olhar para as políticas públicas. In: ENCONTRO DA ASSOCIAÇÃO BRASILEIRA DE CIÊNCIA POLÍTICA, 6., 2008, Campinas. Anais... São Paulo: ABCP, 2008b. 1 CD-ROM.

LOTTA, G. S. Implementação de políticas públicas: o impacto dos fatores relacionais e organizacionais sobre a atuação dos burocratas de nível da rua no Programa Saúde da Família. 2010. Tese (Doutorado em Ciência Política) - Faculdade de Filosofia, Letras e Ciências Humanas, Universidade de São Paulo, São Paulo, 2010.

LOTTA. G. S. e PAVEZ, T. Agentes de implementação e a mediação de políticas públicas: entre dinâmicas e estruturas relacionais. In:

ENCONTRO ANUAL DA ANPOCS, 32., 2008, CAXAMBU. Anais... São Paulo: Anpocs, 2008. 1 CD-ROM.

MINISTÉRIO DA SAÚDE - MS. Relatórios de pesquisa. Disponível em: http://dtrzoo2.saude.gov. br/ascom/indicadorespsf/intr_sint.htm. Acesso em: o9 maio 2005. 
MINISTÉRIO DA SAÚDE - MS. Gabinete do Ministro. Portaria n. ${ }^{\circ} 648$, de 26 de março de 2006. Aprova a Política Nacional de Atenção Básica, estabelecendo a revisão de diretrizes e normas para a organização da Atenção Básica para o Programa Saúde da Família (PSF) e o Programa Agentes Comunitários de Saúde (PACS). Diário Oficial da União, Brasília, DF, 29 mar. 2006.

MISCHE, A. Partisan publics: communication and contention across Brazilian youth activist networks. New Jersey: Princenton University Press, 2007.

NOGUEIRA, R. et al. A vinculação institucional de um trabalhador sui generis: o agente comunitário de saúde. Texto para discussão 735, 2000. Disponível em: http://www.ipea.gov.br/pub/td/ td_200o/tdo735.pdf. Acesso em: 15 dez. 2011.
PIERUCCI, A. F. Linguagens autoritárias, voto popular. In. DAGNINO, E. (Org.). Anos 9o: política e sociedade no Brasil. São Paulo: Brasiliense, 1994. p.137-149.

RAO, V.; WALTON, M. Culture and public action. Stanford: Stanford University Press, 2004.

RIBEIRO, G. L. Ambientalismo e desenvolvimento sustentado: nova ideologia/utopia do desenvolvimento. Revista de Antropologia, São Paulo, São Paulo, n. 34, p.23-31, 1991.

SPINK, P. O lugar do lugar na análise organizacional. Revista de Administração Contemporânea, Rio de Janeiro, v. 5, p. 11-34, 2001. Edição especial.

WOLF, E. R. Aspects of group relations in a complex society: Mexico. American Anthropologist, Arlingtonv, 58, n. 6, p. 1065-1078, Dec. 1956. New Series. 